KUN GAO, Ph.D. candidate ${ }^{1}$

(Corresponding author)

E-mail: 93gaokun@tongji.edu.cn

LIJUN SUN, Ph.D. ${ }^{1}$

E-mail: Ljsun@tongji.edu.cn

${ }^{1}$ College of Transportation Engineering, Tongji University

Key Laboratory of Road and Traffic Engineering of the

Ministry of Education, 4800 Cao'an Road,

JiaDing District, Shanghai, 201804, P. R. China
Traffic in the Cities Original Scientific Paper Submitted: 3 Apr. 2017 Accepted: 28 Nov. 2017

\title{
INCORPORATING INERTIA IN MODE CHOICE AND INFLUENTIAL FACTORS OF CAR STICKINESS: IMPLICATIONS FOR SHIFTS TO PUBLIC TRANSIT
}

\begin{abstract}
To explore efficient strategies of adjusting travel mode structure and support scientific implements of public transit system, this paper investigated travelers' mode choice behavior in a multimodal network incorporating inertia in utility specifications. Comprehensive stated preference surveys considering four modes and four key decisive variables were designed, and face-to-face investigations were conducted to collect reliable data in Shanghai. The discrete choice technique considering mode-specific inertias was employed for modeling. The influencing factors of car stickiness were particularly explored. The results show that there are significant and mode-specific inertias in travelers' choices of travel mode. The inertia of car users shifting to other modes is considerably large compared to inertias of public transit users. Travel time reliability and crowdedness in public transit are identified to be crucial factors influencing car users' willingness to use public transit. Demographic attributes (age, income, education level and gender), spatial context features (commuting duration) and the regime of flexible work time are found to be significant influential variables of car stickiness. Moreover, direct and cross elasticity analyses were executed to show practical implications of shifting car users to public transit. The results provide serviceable support for transport planning and strategy making.
\end{abstract}

\section{KEY WORDS}

mode choice; mode-specific inertia; influential factors; car stickiness; elasticity analysis;

\section{INTRODUCTION}

Excessive private car usage in Chinese metropolises has led to increasingly severe transport issues like traffic congestion and air pollution. Transport managers in Shanghai have taken several management measures to alleviate the problems and tried to shift car users to the more sustainable public transit (PT). New transport facilities like park and ride (P\&R) and bus rapid transit (BRT) have been established, and promoting policies (e.g. discounts for using $P \& R$ ) have been implemented simultaneously, aiming to attract car users. Unfortunately, the adopted measures have not lived up to the expectations and failed to attract a prospective amount of private car users to shift to PT [1]. Transport practitioners are eager to know the exact efficient methods for switching private car users to more sustainable alternatives, and this requires indepth investigations towards travelers' mode choice behavior in a multimodal network.

Mode choice behavior has been traditionally modeled using microeconomic theories based on the assumption that the individual selects the one with the maximum expected utility among all available alternatives after trade-offs between attributes (called “ideal maximization"). Nevertheless, it has been noted in recent behavior studies that travelers might not be totally in line with the "ideal maximization" assumption in some situations, such as repeated commuting trips. Commuting trips mainly take place during a certain period and repeat again and again over time. The repeated travel context results in the potential inertia component in the process of mode choice decision [2]. Commuters are not willing to invest much extra effort to search for the best choice among alternatives every day and tend to reuse the satisfying past selection in a stable travel context $[3,4]$, namely "inertia" or "habitual travel". When travelers face new alternatives, the inertia represents the inclination to stick with a past choice or indisposition to change [5, 6]. Due to the existence of inertia in mode choice, travelers might not be sensitive to changes in external alternatives. Consequently, the effectiveness of travel demand management systems, which are designed to attract car users to other modes is likely to be attenuated. This is exactly the dilemma happening in Shanghai. Unfortunately, the influences of inertia in mode choice have been hardly considered in transport planning or appraisal in China due to the fact that scarce work has 
been conducted in Chinese contexts to measure the scale of inertia and the influential factors that shape inertia in mode choice.

The primary objective of this paper is to incorporate and quantitatively measure travelers' inertia in mode choice and to investigate potential factors influencing car users' stickiness (or preference) based on a unique dataset of mode choice in Shanghai. Comprehensive stated preference scenarios for the multimodal network were established by efficient design methodology. Face-to-face interviews were carried out to collect the behavioral data. The mode-specific inertias in choice of commuting mode were investigated through the discrete choice model. The influential factors of car stickiness were explored to better explain the heterogeneity in predilection for car travel. Moreover, an elasticity analysis was carried out to provide practical implications for shifting car users to PT.

The remainder of this paper firstly gives an overview of current literature about modeling inertia in mode choice and car stickiness. In Section 3, survey instrument development, data collection process, and the modeling methodology are provided. The analysis results are presented in Section 4, followed by a dis cussion and concluding remarks.

\section{LITERATURE OVERVIEW}

This section will present the state of the art with respect to modeling inertia in mode choice and summarize the existing literature that has explored influencing factors of car stickiness.

\subsection{Modeling inertia in travel choice}

Modeling inertia in travel choice has been an important topic in transportation due to its bearing on travel demand forecasting and management strategies. Daganzo and Sheffi [7] proposed a modeling function with inertia to estimate the multinomial probit model. John and Hensher [8] extended the method and implemented it in a two-period panel dataset. Ben Akiva and Morikawa [9] put forward a modeling methodology for travel switching behavior using mixed stated preference (SP) and revealed preference (RP) data by incorporating the inertia effect in the constants of a utility function. Afterwards, the effects of inertia in travel choice were frequently modelled by incorporating constants or dummy variables representing previous choice $[10,11]$ in utility functions, which became the most commonly employed methods in subsequent literature.

More recently, Cantillo et al. [5] modeled the discrete choice of travel mode in the presence of inertia and serial correlation and discussed the effects of integrating the inertia and serial correlation in specifications. In their work, the inertia was defined as a function of the previous deterministic valuation of the alternatives. Yáñez et al. [6, 12] extended the method proposed by Cantillo et al. [5] and added the shock effects in modeling based on panel survey data. Cherchi and Manca [13] tested and compared several measures of travel inertia proposed for both short and long RP panel datasets. Cherchi and Cirillo [14] and Ramadurai and Karthik [15] studied the impacts of inertia on travel choice behavior using short or continuous panel dataset. Their results all indicated obvious inertia in repeated travel contexts. In addition, some studies $[6,10-13,16]$ tried to address the issue of which type of data (RP, SP, or mixed RP/SP) was the better dataset to for stable modeling and measuring the effects of inertia in travel choice.

In the existing literature, no matter what dataset was used, the considered LOS variables in scenarios were generally cost and travel time when analyzing inertia. It was noted that one of the underlying reasons of inertia was the uncertainty and potential risk in new alternatives (e.g. the travel time uncertainty and probability of overcrowding) $[17,18]$. Nevertheless, scarce studies have measured the inertia quantitatively with the presence of travel time reliability and in-vehicle crowding in scenarios. This study incorporates the two attributes as well as monetary cost and travel time in SP scenarios. Moreover, most studies have focused on the modeling method and generally used generic inertia terms for different modes, thus ignoring the potential differences in users' inertia for different modes. This study investigates the mode-specific inertia to identify the potential differences among modes.

\subsection{Influencing factors of car stickiness}

The generally applied methods to investigate the influential factors of car stickiness can be categorized into two aspects: the econometric approach and social-psychological approach. For econometric methodology, factors such as car availability, income, expenditure for car usage, distance/travel time to work, and seasonal public tickets have been identified as the influential factors of habitual car use or car stickiness. For example, González and Marrero [19] showed that increases in energy prices were associated with reduced car usage. Nordfjærn et al. [20] indicated that higher income was related to higher car usage. Zhou [21] demonstrated that commute distance was positively related to carpooling and telecommuting.

Psychological factors, including attitudes, norms, and motivations, also play important roles in shaping travel preferences $[22,23]$. One of the prominent psychological theories to explain car stickiness is the Norm-Activation Model (NAM) [24]. It argues that the environmental norms sacrificing personal interests for benefit of others were relevant to reduction in car stickiness [25]. Empirical studies have shown that the 
NAM could predict the use of transport modes to some extent [22]. It has been indicated that individuals with pro-environmental cognitions tend to decrease car use [26]. Another commonly used approach is the theory of planned behavior (TPB) [27]. Positive attitude towards cars (e.g. flexible and comfortable environment) was found to be one of the underlying reasons of car stickiness [22, 25]. Moreover, the extra psychological effects attached to cars (e.g. social status and power) have been revealed as significant factors of car preference as well [23].

In this paper, we examine the relationship of car stickiness with various factors, including demographic characteristics, spatial context features, and time schedule variables. We especially investigate the impacts of demand management policy: flexible work time on car stickiness. Flexible work time was declared to be helpful in scattering traffic demand over different times and thus alleviating traffic congestion in peak hours. Nevertheless, its potential effects on mode preference are scarcely investigated.

\section{METHODOLOGY}

This section firstly introduces the process of survey design and data collection. Afterwards, the used model specifications are presented, followed by model calibration process.

\subsection{Survey design and data collection}

The used data was collected in 2016 and referred to travelers' mode choice for commuting trips in Shanghai, China. Two-stage surveys were conducted to build the data bank. At the first stage, a survey was carried out to collect the general trip information on commuters in Shanghai. The first-stage survey identified the most decisive attributes influencing travelers' mode choice behavior and provided prior information for the statistical aspect of subsequent scenario design (e.g. the levels of different attributes). In the second stage, a comprehensive questionnaire was generated to quantitatively measure commuters' mode choice behavior. The questionnaire contains three parts: (1) information about the respondent's current commuting trip (e.g. the type of mode, commuting time, commuting distance, and cost); (2) SP scenarios; (3) personal information. Based on the results from the first stage, four commonly used modes for commuting in Shanghai - car, metro, P\&R, and bus - are included in SP scenarios. LOS variables including cost, travel time (TT), travel time reliability (TTR), and in-vehicle crowding are considered for each mode. The TTR is measured by standard deviation (SD) of travel time as recommended by several researchers [28]. The levels of each attribute for each mode in the design are based on the obtained prior information from the first stage and transport experts' experience in Shanghai. Details about the level settings are shown in Table 1.

A specialized software for designing discrete choice instruments, Ngene, was employed to generate the statistical contents of scenarios via D-error efficient design. 18 scenarios with the best utility balance were selected and divided into three blocks. Six scenarios were presented to each respondent. For the presentation of TTR, interviews were carried out to compare understandability of several presenting formats [29] in the literature for Chinese respondents. Presenting travel time distribution to respondents by the pattern of histogram was found to be a comparatively better pattern of representing travel time reliability. One example of the scenarios is illustrated in

Table 1 - Attributes and levels used in the design (18 scenarios in 3 blocks)

\begin{tabular}{|c|c|c|}
\hline Alternative & Attributes & Levels \\
\hline \multirow{4}{*}{ Car } & $\begin{array}{l}\text { Regular travel } \\
\text { time }\end{array}$ & $4(15,25,35,40) \min$ \\
\hline & $\begin{array}{l}\text { Travel time } \\
\text { unreliability (SD) }\end{array}$ & $4(4,8,12,18) \min$ \\
\hline & $\begin{array}{l}\text { Cost (oil, parking } \\
\text { fare, tolls) }\end{array}$ & $4(20,25,35,45) \mathrm{RMB}$ \\
\hline & $\begin{array}{l}\text { Crowding inside } \\
\text { car }\end{array}$ & $1(0)$ \\
\hline \multirow{4}{*}{ Metro } & $\begin{array}{l}\text { Regular travel } \\
\text { time }\end{array}$ & $4(30,40,50,60) \min$ \\
\hline & $\begin{array}{l}\text { Travel time } \\
\text { unreliability (SD) }\end{array}$ & $4(2,4,6,8) \min$ \\
\hline & Cost (ticket) & $3(3,4,5) \mathrm{RMB}$ \\
\hline & $\begin{array}{l}\text { Crowding inside } \\
\text { metro }\end{array}$ & 3 (Level 1, 2, 3) \\
\hline \multirow{4}{*}{$P \& R$} & $\begin{array}{l}\text { Regular travel } \\
\text { time }\end{array}$ & $4(25,35,45,55) \min$ \\
\hline & $\begin{array}{l}\text { Travel time } \\
\text { unreliability (SD) }\end{array}$ & $4(2,6,8,10) \min$ \\
\hline & $\begin{array}{l}\text { Cost (oil, parking } \\
\text { fare, ticket) }\end{array}$ & $4(12,16,18,22) \mathrm{RMB}$ \\
\hline & $\begin{array}{l}\text { Crowding inside } \\
\text { transit }\end{array}$ & 3 (Level 1, 2, 3) \\
\hline \multirow{4}{*}{ Bus } & $\begin{array}{l}\text { Regular travel } \\
\text { time }\end{array}$ & $4(30,40,50,60) \min$ \\
\hline & $\begin{array}{l}\text { Travel time } \\
\text { unreliability (SD) }\end{array}$ & $4(4,8,14,20) \min$ \\
\hline & Cost (ticket) & $3(1,2,3) \mathrm{RMB}$ \\
\hline & $\begin{array}{l}\text { Crowding inside } \\
\text { bus }\end{array}$ & 3 (Level 1, 2, 3) \\
\hline
\end{tabular}

Note: The cost of metro is constrained by its travel time (TT) in the design; when $T T=30$ or 40 , cost $=3$; when $T T=50$, cost $=4$; when $T T=60$, cost $=5$. Crowding level 1: uncrowded with seats; level 2 : standing in uncrowded carriage; level 3: standing in very crowded carriage; $1 \mathrm{RMB}=0.146$ dollar. 
1. Assuming that you go to work from home, you can choose any one of four modes described below. Which one do you prefer the most? (Note: Travel time distribution stands for reliability of the mode)

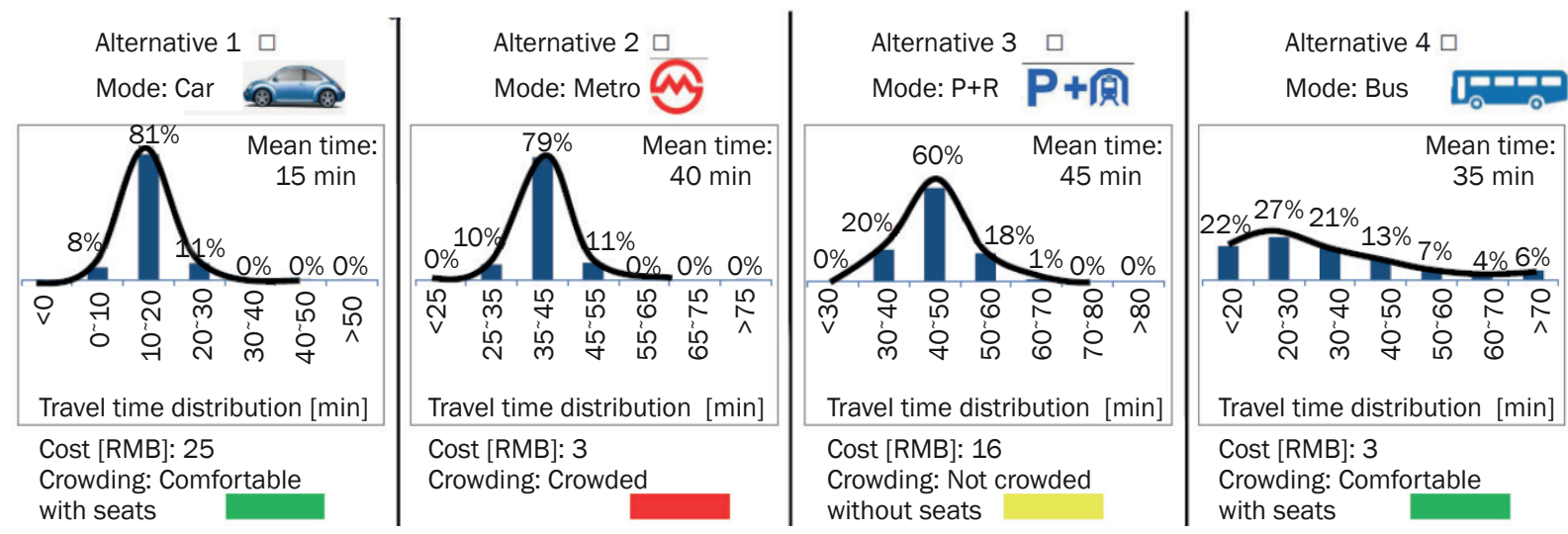

Figure 1 - An example of an SP choice scenario

Figure 1. The distributions of travel time are assumed to be log-normal [30]. A pilot survey was carried out to test the validity of survey design (e.g. questions interpretation and understandability). The data from the pilot survey was used to provide prior information (e.g. preset parameters) for the formal SP scenarios design. Afterwards, the formal scenarios were generated.

In the last part of the questionnaire, personal information was gathered, including demographic characteristics (gender, age, education, occupation, income, car ownership, etc.), spatial context features of commuting (regular travel time and distance in commuting), and time schedule information. The investigated factors of time schedule information contain departure constraints ("cannot depart early because I have to make a meal or send kids to school before work") and flexible work time (work arrival or departure times are strictly fixed or flexible).

Both online surveys and face-to-face interviews were conducted to collect data at first. Nevertheless, the data collected online was not as representative as that from face-to-face interviews. For the sake of validity of data resources, some investigators were recruited to conduct face-to-face and one-on-one surveys. The targeted respondents were commuters who owned private cars. Commuters without private cars were not in accordance with the provided scenario. With the assistance of traffic police departments, surveys were carried out in two working halls of the Bureau of Vehicle Management in Shanghai, which deals with car-related affairs (e.g. traffic violations). Most of the respondents were car owners or potential car owners (applied for car license but not yet received due to car license auction in Shanghai). People over 60 years old were not surveyed since most of them were retired. The respondents were requested to read and understand questions carefully with the help of investigators. Finally, 342 (2,052 observations) effective questionnaires were collected after filtering.
All respondents are summarized in Table 2. The percentage of car owners in the data bank is $84 \%$. Among effective respondents, 52.5\% used private cars, $10.4 \%$ used P\&R, and $37.1 \%$ adopted public transit/others as common commuting modes although most of them had private cars.

\subsection{Model specifications and estimation}

The determined utility $U_{j q t}$ of alternative $j$ perceived by individual $q$ in period $t$ could be expressed by Equation 1.

$$
\begin{aligned}
& U_{j q t}=\sum_{k} \alpha_{q k} x_{j k t}+P_{j q}\left(z_{q m}, \beta_{q m}\right)+\varepsilon_{j q t} \\
& P_{j q}=\left(z_{q m}, \beta_{q m}\right)=\sum_{m}\left(\beta_{q m} z_{q m}\right)+G_{j q} \\
& G_{j q}=\overline{G_{j}}+\gamma \cdot \sigma_{j}
\end{aligned}
$$

$x_{j k t}$ is a vector of explanatory variables of alternative $A_{j}$, including cost, average travel time, in-vehicle crowding, and TTR. The $\alpha_{q k}$ is the corresponding $(1 \times K)$ vector of parameters. Three crowding levels were set in the survey. In the estimation, the crowding level "uncrowded with seats" was regarded as the base level, and two dummies (CR1 and CR2) were defined in the utility function to denote the situations of crowding level 2 ("standing in uncrowded carriage") and crowding level 3 ("standing in very crowded carriage"), respectively. The TTR is measured by standard deviation of travel time as recommended by Kouwenhoven et al. [31] $P_{j q}\left(z_{q m}, \beta_{q m}\right)$ is the component standing for individual $q$ 's preference for alternative $j$. The $P_{j q}\left(z_{q m}, \beta_{q m}\right)$ for car denotes the degree of car stickiness. $G_{j q}$ is a random variable representing the distaste or predilection for alternative $j . \bar{G}_{j}$ is the mean value of populations. $\sigma_{j}$ is a random term representing the heterogeneity among respondents and set to be of normal distribution with the mean value of $0 . \gamma$ is the scaled parameter. $z_{q m}$ is the potential influential factor of individual predilection for alternative $j . \beta_{q m}$ is the homologous $(1 \times m)$ 
Table 2 - Descriptions of attributes of effective respondents

\begin{tabular}{||l|l||}
\hline \multicolumn{1}{|c|}{ Personal attributes } & \multicolumn{1}{c||}{ Statistics } \\
\hline \hline Age & $\begin{array}{l}\text { Less than 30 years old (named as young group herein, 41\%), 30 40 (40\%), 40 50 (13\%), } \\
\text { more than 50 years old (3\%), skipped (3\%) }\end{array}$ \\
\hline Education level & $\begin{array}{l}\text { Level 1: lower than undergraduate (27\%), Level 2: Undergraduate (46\%), Level 3: Master } \\
\text { (21\%), Level 4: Doctor (2\%), skipped (4\%) }\end{array}$ \\
\hline $\begin{array}{l}\text { Monthly income (RMB) } \\
\text { (1 RMB = 0.152 dollar) }\end{array}$ & $\begin{array}{l}\text { Less than 3,000 (5\%), 3,000 6,000 (27\%), 6,000 10,000 (36\%), 10,000 20,000 (20\%), } \\
\text { more than 20,000 (7\%), skipped (5\%) }\end{array}$ \\
\hline Gender & Male (63\%), female (37\%) \\
\hline Car ownership & Yes (84\%), Plan to get one and applying for license plate (16\%) \\
\hline Commuting time & $\begin{array}{l}\text { Less than 30 min (short commuting time, 36\%),30 60 min (48\%), more than 60 min (long } \\
\text { commuting time, 16\%) }\end{array}$ \\
\hline Commuting distance & $\begin{array}{l}\text { Less than 10 km (short commuting distance, 39\%),10 20 km (40\%), over 20 km (long } \\
\text { commuting distance, 21\%) }\end{array}$ \\
\hline Departure constraint & Yes (46\%), No (54\%) \\
\hline Flexible work time & Yes (31\%), No (69\%) \\
\hline
\end{tabular}

vector of parameters. $\varepsilon_{q j t}$ is the random error term with independent and identically (IID) extreme value distribution herein for logit models.

If the individual $q$ used the alternative $A_{r}$ at the initial time $t$ and some changes happened in the attributes of choices, the probability that the individual switches from his original choice $A_{r}$ to new alternative $A_{j}$ could be expressed by Equation 2 .

$$
\begin{aligned}
& P_{q t}\left(S_{r \rightarrow j}\right)= \\
& =P\left(U_{j q t}-U_{r q t} \geq I_{r j q t} \& U_{j q t}-U_{i q t} \geq I_{j q r t}-I_{\text {irqt }}\right) \\
& j \neq r \text { or } i \\
& I_{j r q t}=\lambda_{r} F_{j r q t}(\psi)
\end{aligned}
$$

$I_{j r q t}$ is the inertia of switching from original mode $A_{r}$ to new alternative $A_{j}$. If the inertia is equal to zero, there is no inertia. If it is positive, it means that the individual is resistant to change and if negative, it implies that the individual has disposition to change. The latter may occur when the person is not satisfied with the previously chosen mode and seeks a better alternative. The $\lambda_{r}$ is a dummy variable and is 1 when the previously used mode is $r$, otherwise 0 . The term $F_{j r q t}(\psi)$ represents the scale of inertia and could be dummy variables representing previous travel experience or a function of related variables $\psi$ (e.g. the LOS variables or utility) [5, $6,13]$. Cherchi and Manca [13] tested several existing measures of $F_{j r q t}(\psi)$. The results showed that using dummy variables could usually get significant results, and using more complex expressions (e.g. measuring inertia by weighted utilities of the previous experiences) might not be superior to simpler expressions for inertia. In this paper, we adopted dummy variables that represent previous travel experience to express the inertia. The final utility function of car in estimation could be expressed as Equation 3 and those for other modes as Equation 4. The term $\sum \beta_{q m} z_{q m}$ is incorporated in the utility specification of car travel to investigate potential influential factors towards car stickiness. The preference terms $G_{j q t}$ and inertia terms $I_{j q t}$ of different modes are set to be mode-specific.

$$
\begin{aligned}
& U_{r q t}=\sum_{k} \alpha_{q k} x_{r k t}+G_{r q}+\sum_{m}\left(\beta_{q m} z_{q m}\right)+I_{r q t}+\varepsilon_{r q t} \\
& U_{j q t}=\sum_{k} \alpha_{q k} x_{j k t}+G_{j q}+I_{j q t}+\varepsilon_{j q t}
\end{aligned}
$$

The mixed logit model (or random parameter logit model) is employed for parameter estimations since it is capable of capturing travelers' heterogeneities. On account of the variations in preference and inertia, the preference term $G_{j q t}$ and inertia term $I_{j q t}$ were set to be random parameters with normal distributions. Given the fact that a respondent actually made a sequence of scenarios in one questionnaire, a panel data process was performed to consider panel effects in the estimation. It ensures unobserved preference heterogeneity among individuals and preference homogeneity for one individual over a series of choices. The error component model was performed firstly to examine several nested structures and to capture the possible correlations between modes (e.g. bus, metro, and $\mathrm{P} \& \mathrm{R})$. It turned out that the correlation parameter was not significantly different from 1 .

In analyzing influential factors of car stickiness, all potential factors $z_{q m}$ collected in the survey were tested. The non-significant factors were rejected step by step until all coefficients were statistically significant at the 95\% confidence level. The parameters for the influencing factors of car stickiness are all dummy variables in the utility specification. For instance, when commuting time is longer than 60 minutes, the value of the parameter "long commuting time" is 1 , otherwise zero. This goes for all other parameters. For the gender, the parameter is 1 when the individual is male and otherwise is zero. The parameters for high 
income, young age, and high education are equal to 1 when pre-tax monthly income is over ten thousand $\mathrm{RMB}$, age is below 30 years old, and education degree is beyond master, respectively. "Departure constraint" denotes that commuters could not depart for work before a certain time because of duties like making breakfast or sending kids to school. The parameter of "departure constraint" is 1 for those with departure constraints. Flexible work time is equal to 1 for those who have flexible working hours. Professional package for discrete choice modeling Nlogit 5 [32] was applied to implement the estimation process.

\subsection{Calculation of elasticity}

Direct elasticity and cross elasticity of each attribute of each mode were calculated to analyze how the mode share would respond to changes in attributes and provide implications for traffic management. In this context, direct elasticity of one attribute is defined as how responsive are changes of the choice probability of a mode to changes in the attribute of the mode. The cross elasticity of attribute $K$ of mode A to mode $B$ is the changes of the choice probability of mode $B$ corresponding to changes in attribute $K$ of mode $A$. Direct elasticity and cross elasticity are calculated by Equations 5 and 6, respectively. Details of derivation for the equations are available in Hensher and Greene [33]. Because of the existence of random parameters and the impacts of personal characteristics on car stickiness, simulations were conducted to calculate the weighted elasticities. 10,000 draws were generated in calculations according to the estimated distributions of random parameters and statistical results of respondents' attributes. It should be noted that the direct elasticity and cross elasticity are related to the choice probability of the mode in a scenario and vary among different scenarios. There were 18 scenarios in our survey. 18 values were obtained for the elasticity of each attribute of each mode, and the mean value of the 18 scenarios is selected as the representative value.

$$
\begin{gathered}
E\left(x_{i k}, P_{i n}\right)=\frac{\frac{\partial P_{i n}}{P_{i n}}}{\frac{\partial x_{i k}}{x_{i k}}}=-\beta_{i k n} x_{i k} P_{i n}\left(1-P_{i n}\right) \\
C E\left(x_{i k}, P_{j n}\right)=\frac{\frac{\partial P_{j n}}{P_{j n}}}{\frac{\partial x_{i k}}{x_{i k}}}=-\beta_{i k n} x_{i k} P_{i n}, j \neq i
\end{gathered}
$$

$E\left(x_{i k}, P_{i n}\right)$ and $C E\left(x_{i k}, P_{j n}\right)$ are elasticity and cross elasticity. $i, k$, and $n$ are the indexes of mode, attribute and individual respectively. $P_{i n}$ denotes the choice probability of mode $i . x_{i k}$ is the value of attribute $k$ of mode $i$. $\beta_{i k n}$ is the coefficient of attribute $k$.

\section{RESULTS AND ANALYSIS}

This section presents the estimated results of the models proposed in the last section. Firstly, the results of mode choice inertia are demonstrated and then the found influential factors of car stickiness are shown, followed by the results of the elasticity analysis.

\subsection{Inertia in mode choice}

Table 3 reports the estimated result. The mean values of inertia terms are all significant at $95 \%$ confidence level. This manifests that the previously used mode or past commuting experience indeed has significant

Table 3 - Estimated results

\begin{tabular}{|l|c|c|c|}
\hline \multicolumn{1}{|c|}{ Parameters } & $\begin{array}{c}\text { Estimated } \\
\text { Value }\end{array}$ & $Z$ value & $P$ value \\
\hline \hline Cost & -0.07057 & -7.40 & $<0.001$ \\
\hline $\begin{array}{l}\text { Average travel } \\
\text { time }\end{array}$ & -0.04982 & -11.66 & $<0.001$ \\
\hline $\begin{array}{l}\text { Travel time } \\
\text { reliability }\end{array}$ & -0.08821 & -11.97 & $<0.001$ \\
\hline CR1 & -0.79867 & -8.51 & $<0.001$ \\
\hline CR2 & -1.20092 & -13.97 & $<0.001$ \\
\hline Inertia for car & 0.90926 & 5.76 & $<0.001$ \\
\hline $\begin{array}{l}\text { SD of inertia for } \\
\text { car }\end{array}$ & 0.07916 & 0.33 & 0.745 \\
\hline Inertia for metro & 0.48687 & 3.64 & $<0.001$ \\
\hline $\begin{array}{l}\text { SD of inertia for } \\
\text { metro }\end{array}$ & 0.66143 & 3.73 & $<0.001$ \\
\hline Inertia for P\&R & 0.37947 & 2.99 & $<0.001$ \\
\hline $\begin{array}{l}\text { SD of inertia for } \\
\text { P\&R }\end{array}$ & 0.06358 & 0.17 & 0.863 \\
\hline Inertia for bus & 0.17988 & 2.14 & 0.03 \\
\hline $\begin{array}{l}\text { SD of inertia for } \\
\text { bus }\end{array}$ & 0.45314 & 0.62 & 0.535 \\
\hline$G_{\text {car }}$ & 1.81270 & 4.63 & $<0.001$ \\
\hline SD of $G_{\text {car }}$ & 0.74467 & 7.10 & $<0.001$ \\
\hline $\begin{array}{l}\text { Long commuting } \\
\text { time }\end{array}$ & -0.51580 & -2.79 & 0.003 \\
\hline Young age & 0.39672 & 2.68 & 0.007 \\
\hline $\begin{array}{l}\text { Flexible work } \\
\text { time }\end{array}$ & 0.30104 & 2.10 & 0.035 \\
\hline High salary & 0.43042 & 2.64 & 0.008 \\
\hline High education & 0.52599 & 2.97 & 0.003 \\
\hline Male & 0.19576 & 2.42 & 0.010 \\
\hline$G_{P \& R}$ & 1.16511 & 5.54 & $<0.001$ \\
\hline SD of $G_{P \& R}$ & 0.54245 & 3.73 & $<0.001$ \\
\hline$G_{\text {metro }}$ & 0.87045 & 7.94 & $<0.001$ \\
\hline SD of $G_{\text {metro }}$ & 0.08922 & 0.33 & 0.741 \\
\hline$G_{\text {hus }}$ & 0 (fixed) & - & - \\
\hline
\end{tabular}

Note: $S D$ denotes standard deviation. Log likelihood function $=$ -2095.18558, Model significance level<0.0001, McFadden pseudo $R$-squared $=0.347, A I C=4240.4, A I C / N=2.064$. Non-significant coefficients are in italic. 
effects on commuters' current mode choice behavior. The inertia terms are all positive, indicating that travelers show resistance to changing original mode and present inertia in mode shift. More specifically, the estimated value of the inertia term of car travel is up to 0.90926 and equivalent to the incremental utility of 18-minute reduction in travel time according to the marginal utility of average travel time. It reveals that habitual car users show strong inertia in mode shift and are unwilling to switch from private cars to public transit. The inertia term of car travel is $86.7 \%$ higher than the estimated inertia term of metro $(0.48687)$ and $140 \%$ higher than that of P\&R (0.37947), respectively. The inertia term of bus travel is the lowest at 0.19788 , implying that current bus users show slight inertia in mode shift. The results demonstrate that the inertias of different modes are obviously distinct and show mode-specific characteristics.

The standard deviation (SD) of inertia term for metro is significant at $95 \%$ confidence level and is 0.66143 , which is even higher than the estimated mean value. It implies the existence of a large heterogeneity in inertia terms among different metro users. Based on the results, it could be deduced that some metro users may show negative inertia and disposition to change to other modes. The SDs of the inertia terms of car travel and P\&R are not significant and very low. The SD of inertia term of bus travel is much higher than the mean value but not significant in the statistical tests.

The reliability ratio (the ratio of marginal utility between reliability and average travel time) is about 1.7 on average and above 1 , indicating that respondents highly value certainty of travel time in mode choice. For crowding, reduction from level 3 "standing in very crowded carriage" to base level "uncrowded with seats" is equal to the incremental utility of a decrease of 24 minutes of travel time. The results imply that in-vehicle crowding and uncertainty in travel time of public transit have remarkable negative impacts on car users' willingness to shift.

\subsection{Influential factors of car stickiness}

It can be seen from the estimated mode-specific constant $G_{j}$ that car travel is the most preferential mode. The estimated $G_{c a r}$ is 1.73525 and equivalent to the incremental utility of reducing 33 minutes of travel time. The $G_{c a r}$ is $55.6 \%$ higher than $G_{P \& R}$ (1.16511) and $108.2 \%$ higher than $G_{\text {metro }}(0.87045)$ separately. It indicates that the respondents (most of whom are car owners) have strong stickiness towards car. The $G_{b u s}$ is the lowest, demonstrating that bus is least preferred and has little attraction for car users. The $G_{P \& R}$ is higher than the $G_{m e t r o}$. The newly introduced combined travel mode P\&R seems to be more attractive than metro/bus.
The statistically significant influential factors of car stickiness are demonstrated in Table 3. Demographic characteristics including age, income, education level, and gender are identified as significantly associated with respondents' car stickiness. More specifically, the coefficient of "high education" is positive at 0.53317 . It indicates that respondents with high education have stronger car stickiness. The coefficient of "high salary" is 0.43042 , which implies that those with high income show more preference for car use. It may be because travelers with high income or better education are much more affluent and can afford more expensive travel choices. They prefer more comfortable modes like private cars and show aversion to unpleasant environment in public transit commuting. Further, males are revealed to show more preference for car use. The finding is in line with the findings of Bergstad et al. [34] Respondents of young age are found to be comparatively preferring car use. This may be ascribed to the phenomenon that car usage is generally regarded as a social status symbol by youngsters in China.

For the spatial context, the coefficient of "Iong commuting time" is negative $(-0.62791)$ and significant at 99\% confidence level. It means that respondents with longer commuting times show less car stickiness. This may be explained by the fact that for long commuting time (over $60 \mathrm{~min}$ ), private car has no conspicuous advantages over rapid transit in travel time in Shanghai. Simultaneously, driving a long time is exhausting during the commuting period, while taking public transit may free travelers to do something else while commuting. The coefficient of "flexible work time" is positive. It is interesting to find that in demand management "flexible work time" is associated with stronger car stickiness. Flexible work time is expected to scatter travel demands over different periods to alleviate traffic congestion. However, the results reveal that flexible work time may potentially lead to stronger car stickiness.

The higher the absolute value of the coefficient of an influential factor is, the greater impact the factor will have on respondents' car stickiness. The descending order of the influential factors is "High education", "Long commuting time", "High salary", "Young age", "Flexible work time", and "Male".

\subsection{Direct elasticity and cross elasticity}

Figure $2 a$ demonstrates the results of the elasticity analysis. The sign of direct elasticity should be negative because of the negative correlation of changes in the attributes and the probability of choosing the mode. For a more convenient comparison, the absolute value of direct elasticity is adopted for presentation in this context. For cars, the cost has the highest direct elasticity (1.40), followed by average travel time (0.84), and reliability (0.52). The direct elasticity of 


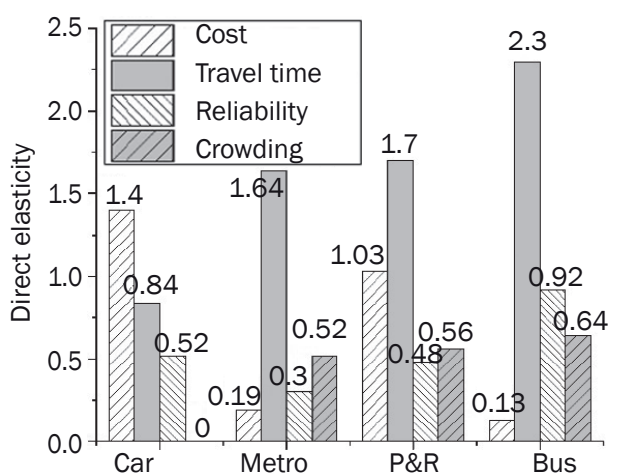

a) Direct elasticity of attributes for the four modes

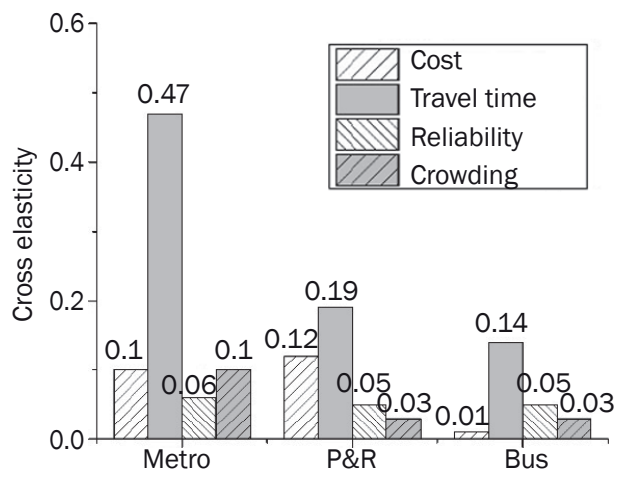

b) Cross elasticity to car

Figure 2 - Elasticity and cross elasticity of attributes

cost is over one, meaning that travel expenditure is one of the elastic variables influencing the probability of choosing car travel. This implies that increases in cost from current levels would remarkably reduce the probability of using car travel. For public transit (PT), the direct elasticity values of average travel times of metro and bus are 1.64 and 2.3, respectively, which are much higher than direct elasticities of other attributes (i.e. cost, reliability, and crowding). This reveals that the probability of choosing metro or bus is considerably sensitive to average travel time. The costs of metro and bus have low direct elasticity values, indicating that the respondents are not sensitive to changes in costs of PT. The direct elasticity values of reliability for metro and bus are 0.3 and 0.92 , respectively. The result demonstrates that improvement in travel time reliability is helpful in boosting the share rate of bus usage but is not so efficient for metro. The direct elasticities for crowding of bus and metro are around 0.6 and close to each other. For P\&R, travel time has the highest direct elasticity (1.7), followed by cost (1.03), crowding (0.56), and reliability (0.48). Reductions in average travel times and costs from current levels are comparatively valid measures to increase the current share of P\&R.

The cross elasticities (CE) of attributes of metro, $P \& R$, and bus to car are illustrated in Figure $2 b$. For metro, the cross elasticity of average travel time $(0.47)$ is the highest, followed by cost $(0.1)$, crowding (0.1), and TTR (0.06). Reduction in mean travel time of metro from current level seems to be relatively efficient in attracting car users. For bus, the calculated CE of travel time is 0.14 , and the CEs of other attributes are all extremely low, which demonstrates that the respondents are not sensitive to improvements in the LOS variables of bus and show indisposition to bus. For P\&R, the CE of average travel time (0.19) is the highest, followed by cost (0.12), TTR (0.05), and crowding (0.03). Decreases in average travel time and cost of P\&R from current level are comparatively more attractive for car users to shift to some extent, while improvements in other attributes seem to make little difference. The CEs of attributes for all three modes are lower than 0.5. This implies that the respondents, most of whom are chronic car users, are not strongly sensitive to improvements of other modes and are unwilling to shift to public transit voluntarily.

\section{DISCUSSION AND IMPLICATION FOR SHIFTS TO PT}

The inertias in mode choice could be explained by several aspects. The repeated choice context shapes people's habits in choice and they will show inertia in switching to new alternatives [3, 35]. Moreover, personal factors like risk aversion [17], learning expenses [18], and resistance to change in psychology [4] are all claimed to be the underlying reasons of inertia in travel choice.

In this study, the inertias of different modes are found to be mode-specific. There are obvious differences in the values of inertia terms of different modes. More specifically, the inertia in switching from car to other modes is much higher than the inertia of public transit. This implies that shifting current car users to PT is tough, while current PT users are comparatively more likely to change to other modes, which is a crucial dilemma for transport managers. Due to the significance of inertia terms and considerable differences in inertias of different modes, it is necessary to incorporate the mode-specific inertia terms in model specifications in case of forecasting bias. The mode-specific inertia terms imply that transport policies like car rationing and numbered license ban (vehicles with even-numbered license plates are only allowed to travel on certain days), which forces car users to use public transit sometimes, could break car users' repeated commuting contexts to some degree and increase their adoption of public transit. This is potentially helpful in reducing car users' inertia in mode choice.

There are two major categorical measures to shift car users to public transit (PT): promoting the benefits of PT (e.g. public transit priority) and increasing the expense of using private cars (e.g. congestion pricing). 
The estimated results indicate that travel time reliability (TTR) and in-vehicle crowding are valued highly by travelers. Hence, improving service quality like travel time certainty and comfort of PT are beneficial to promote the advantages of PT. The results of direct and cross elasticity analysis both show that the share rate of PT (metro, P\&R, and bus) is most sensitive to the changes in mean travel time from current situations. Measures which could decrease travel time of public transit (e.g. public transit lanes and traffic signal priority) seem to be more efficient in attracting car users. The direct and cross elasticities of cost for bus and metro are very low, implying that transport policies like discounts in public transit fees actually do little to attract car users. For the combined travel mode P\&R, car owners are more amenable to it than metro/bus. Travel time reduction and expenditure of P\&R are effective measures to promote its share rate. The cross elasticities of attributes of PT (metro, P\&R, and bus) to car are all low, under 0.5 , indicating that the share rate of car is not much sensitive to changes in LOS variables of PT. The results reveal the unfortunate fact that the service improvements to certain modes of public transport could raise its share rate to some degree, but they do not attract car users remarkably. The increased share rate of one public transport mode actually comes from users of other public transit modes rather than car users. Therefore, only promoting the quality of PT may not live up to the expectations of shifting enough car users to PT.

From the results of elasticities of car travel, it could be seen that the share rate of car travel is sensitive to changes in cost and travel time at current stage. Increasing the expense of using car travel (e.g. congestion pricing and high parking fee) and weakening the priority of private cars in travel are practical methods to force car users to use public transit. Combined with the above elasticity analysis of PT, efficient measures to shift car users should be firstly increasing the cost of car travel to lead car users to consider change and then ensuring the service quality of PT (e.g. bus only lanes and public transit priority to improve travel time) to attract car users at the same time. This strategy refers to psychological principles: an efficient way to break a habit is making changes in the original stable context and then offering incentives to choose new alternatives [36]. Meanwhile, it should also be noted that due to the small inertia of current PT users who own cars and their obvious preference for car travel, it is necessary to take corresponding preventive measures to avoid PT users shifting to car travel.

Several factors are identified to be related to car stickiness. Those factors are useful in predicting travelers' degree of car stickiness in transport forecasting models. The regime of flexible work time is revealed to be associated with strong car stickiness, although it has been claimed to scatter travel demand over time and potentially reduce traffic congestion during peak hours.

\section{CONCLUSIONS AND FUTURE WORK}

This paper analyzed the mode choice behavior in a multimodal network considering inertia effects and investigated several types of influential factors towards car stickiness (or preference) based on the unique survey data from Shanghai. The survey incorporated four modes and four decisive attributes, including travel time reliability and in-vehicle crowding in scenarios. Face-to-face interviews were conducted to create a reliable data bank. Discrete choice models were employed to analyze mode choice behavior. Elasticity analysis was conducted to explore the sensitivity of the share rates of modes to changes in level-of-service variables. It has been found that there is a significant and mode-specific inertia in mode choice. The mode-specific inertia terms should be considered in modeling specifications in case of a forecasting bias. Demographic attributes (age, income, education level, and gender), spatial context features (commuting time), and flexible work time regime are identified to be significant influencing factors towards car users' preference for private car travel. The elasticity analyses show that current car users are sensitive to changes in cost and travel time of cars but not obviously sensitive to changes in attributes of other modes. Improving the mean travel time of public transit is comparatively efficient in attracting car users to shift. Some practical implications for shifting car users to public transit have been discussed and proposed according to analytical results.

One of the limitations of this study is that regardless of strong efforts, more samples and even revealed preference data could be collected. Moreover, the results show that travelers highly value the certainty of travel time of alternatives in mode switching. It is interesting to propose a new modeling method using the behavioral theories under uncertainty, such as cumulative prospect theory, to more accurately describe travelers' mode shift behavior and risk aversion characteristics.

\section{ACKNOWLEDGEMENT}

The authors gratefully acknowledge financial support from the National Natural Science Foundation of China (NSFC) under grant number 51678443.

第一作者：高 坤(1993-), 男, 在读博士, 道路与交通工 程教育部重点实验室, 同济大学交通运输工程学院, 中国 上海市嘉定区曹安公路4800号, 201804。

主要研究方向: 交通出行行为建模与分析、交通政策、公 共交通系统。

邮箱: 93gaokun@tongji.edu.cn 
第二作者: 孙立军(1963-), 男, 教授, 博士生导师, 工学 博士，道路与交通工程教育部重点实验室，同济大学交 通运输工程学院, 中国上海市嘉定区曹安公路4800号, 201804 。

主要研究方向: 交通政策与管理、交通智能系统、交通出 行行为

邮箱: ljsun@tongji.edu.cn

考虑惰性的出行方式选择与小汽车偏好影响因素分 析：对公共交通的启示

摘要:

为了探究调整城市出行方式结构和建立科学公共交通 系统的有效方法, 本文分析了考虑惰性的多模式交通网络 出行方式选择行为。本研究设计了考虑四种常用通勤方式 和四种重要影响因素的出行行为调查场景, 采用面对面调 查方法在上海收集了可靠的出行行为数据, 运用考虑情性 的离散选择模型进行行为规律分析, 并探究了出行者对小 汽车偏好的影响因素。结果显示在多模式交通网络的出行 方式选择中, 出行者存在显著的惰性, 且出行者对不同交 通方式的惰性存在明显差异性。小汽车用户转移到新出行 方式的惰性远大于公共交通用户。结果表明行程时间可靠 度与车内拥挤程度是影响小汽车用户使用公共交通意愿的 重要因素。个人经济社会属性（年龄、收入、教育程度和 性别）、通勤时间和弹性工作制被发现是影响小汽车用户 对小汽车偏好的显著因素。另外, 通过弹性分析探究了转 移小汽车用户到公共交通的有效管理措施。本研究为城市 交通出行结构调整、规划与管理提供了理论支撑。

\section{关键词:}

方式选择；不同交通方式的惰性；影响因素；小汽车偏 好; 弹性分析

\section{REFERENCES}

[1] SURCTDRI. Multimodal Transportation Operations Annual Report (Year of 2015). Shanghai Urban and Rural Construction and Transportation Development Research Institute, Shanghai, 2016.

[2] Pendyala RM. Measuring day-to-day variability in travel behavior using GPS data. FHWA, Washington, DC. Final Report, 1999. Available from: http://www. fhwa. dot. gov/ohim/gps.

[3] Verplanken B, Aarts H, Knippenberg AV. Habit, information acquisition, and the process of making travel mode choices. European Journal of Social Psychology. 1997;27(5): 539-560.

[4] Gärling T, Axhausen KW. Introduction: Habitual trave choice. Transportation. 2003;30(1): 1-11.

[5] Cantillo V, Ortúzar JdD, Williams HC. Modeling Discrete Choices in the Presence of Inertia and Serial Correlation. Transportation Science. 2007;41(2): 195-205.

[6] Yáñez MF, Cherchi E, Ortuzar JdD, Heydecker B. Inertia and shock effects on mode choice panel data: implications of the Transantiago implementation. In: Travel Behaviour Research in an Evolving World. Emerald; 2012.

[7] Daganzo CF, Sheffi Y. Multinomial Probit with Time Series Data: Unifying State Dependence and Serial-Correlation Models. Environment and Planning A. 1982;14(10): 1377-1388.

[8] Johnson L, Hensher D. Application of multinomia probit to a two-period panel data set. Transportation Research Part A: General. 1982;16(5-6): 457-464.

[9] Ben-Akiva M, Morikawa T. Estimation of switching models from revealed preferences and stated intentions. Transportation Research Part A: General. 1990;24(6): 485-495.

[10] Bradley MA, Daly AJ. Estimation of Logit Choice Models Using Mixed Stated Preference and Revealed Preference Information. In: Les Methodes D'analyse Des Comportements De Deplacements Pour Les Annees 1990 - 6e Conference Internationale Sur Les Comportements De Deplacements, 22-24 May 1991, Chateau Bonne Entente, Quebec; 1991.

[11] Morikawa T. Correcting state dependence and serial correlation in the RP/SP combined estimation method. Transportation. 1994;21(2): 153-165.

[12] Yáñez MF, Ortuzar JdD. Modeling choice in a changing environment: assessing the shock effects of a new transport system. In: Choice Modeling: The State-ofthe-art and The State-of-practice: Proceedings from the Inaugural International Choice Modeling Conference. Emerald Group Publishing Limited; 2010.

[13] Cherchi E, Manca F. Accounting for inertia in modal choices: some new evidence using a RP/SP dataset. Transportation. 2011;38(4): 679-695.

[14] Cherchi E, Cirillo C. Understanding variability, habit and the effect of long period activity plan in modal choices: a day to day, week to week analysis on panel data. Transportation. 2014;41(6): 1245-1262.

[15] Ramadurai G, Inivasan KK. Dynamics and Variability in Within-Day Mode Choice Decisions: Role of State Dependence, Habit Persistence, and Unobserved Heterogeneity. Transportation Research Record Journal of the Transportation Research Board. 2006;1977(1): 43-52.

[16] González RM, Marrero ÁS, Cherchi E. Testing for inertia effect when a new tram is implemented. Transportation Research Part A: Policy and Practice. 2017:98: 150-159.

[17] Chorus C, Dellaert BGC. Travel Choice Inertia: The Joint Role of Risk Aversion and Learning. Journal of Transport Economics \& Policy. 2010;46(1): 139-155.

[18] Chorus CG. Risk aversion, regret aversion and travel choice inertia: an experimental study. Transportation Planning and Technology. 2014;37(4): 321-332.

[19] González RM, Marrero GA. Induced road traffic in Spanish regions: A dynamic panel data model. Transportation Research Part A: Policy \& Practice. 2012;46(3): 435-445.

[20] Nordfjærn T, Lind HB, Şimşekoğlu Ö, Jørgensen SH, Lund IO, Rundmo T. Habitual, safety and security factors related to mode use on two types of travels among urban Norwegians. Safety Science. 2015;76: 151-159.

[21] Zhou J. Sustainable commute in a car-dominant city: Factors affecting alternative mode choices among university students. Transportation Research Part A: Policy \& Practice. 2012;46(7): 1013-1029.

[22] Bamberg S, Hunecke M, Blöbaum A. Social context, personal norms and the use of public transportation: Two field studies. Journal of Environmental Psychology. 2007;27(3): 190-203.

[23] Steg L. Car use: lust and must. Instrumental, symbolic and affective motives for car use. Transportation Re- 
search Part A: Policy \& Practice. 2005;39(2-3): 147-162.

[24] Schwartz SH, Howard JA. A normative decision making model of altruism. In: Rushton PJ, Sorrentino RM. (eds) Altruism and Helping Behavior: Social, Personality, and Developmental Perspectives. Hillsdale: Lawrence Erlbaum; 1981. p. 189-211.

[25] Nordlund AM, Garvill J. Effects of values, problem awareness, and personal norm on willingness to reduce personal car use. Journal of Environmental Psychology. 2003;23(4): 339-347.

[26] De Groot JIM, Steg L. Relationships between value orientations, self-determined motivational types and pro-environmental behavioural intentions. Journal of Environmental Psychology. 2010;30(4): 368-378.

[27] Ajzen I. The theory of planned behavior. Research in Nursing \& Health. 1991;14(2): 137-144.

[28] Jong GCD, Bliemer MCJ. On including travel time reliability of road traffic in appraisal. Transportation Research Part A: Policy \& Practice. 2015;73: 80-95.

[29] Carrion C, Levinson D. Value of travel time reliability: A review of current evidence. Transportation Research Part A: Policy \& Practice. 2012;46(4): 720-741.

[30] Guessous Y, Aron M, Bhouri N, Cohen S. Estimating Travel Time Distribution under different Traffic conditions.
Transportation Research Procedia. 2014;3: 339-348.

[31] Kouwenhoven M, Jong GCD, Koster P, Berg VACVD, Verhoef ET, Bates J, Warffemius PMJ. New values of time and reliability in passenger transport in The Netherlands. Research in Transportation Economics. 2014;47(1): 37-49.

[32] Metrics C. Ngene 1.1. 1 User Manual \& Reference Guide. Sydney, Australia: ChoiceMetrics; 2012.

[33] Hensher DA, Greene WH, Ho CQ. Random Regret Minimization and Random Utility Maximization in the Presence of Preference Heterogeneity: An Empirical Contrast. Journal of Transportation Engineering. 2016:142(4).

[34] Bergstad CJ, Gamble A, Hagman O, Polk M, Gärling T, Olsson LE. Affective-symbolic and instrumental-independence psychological motives mediating effects of socio-demographic variables on daily car use. Journal of Transport Geography. 2011;19(1): 33-38.

[35] Wood W, Quinn JM, Kashy DA. Habits in everyday life: thought, emotion, and action. Journal of Personality \& Social Psychology. 2003;83(6): 1281-97.

[36] Gardner B. Modeling motivation and habit in stable travel mode contexts. Transportation Research Part F: Traffic Psychology \& Behaviour. 2009;12(1): 68-76. 